\title{
THE NATURE OF PULMONARY HYPERTENSION IN MITRAL STENOSIS
}

BY

\author{
L. G. DAVIES, J. F. GOODWIN, AND B. D. VAN LEUVEN
}

From the Department of Medicine, Postgraduate Medical School of London

Received July 9, 1954

It is known that both functional reversible, and organic, narrowing of the pulmonary arterioles play a part in the increased pulmonary arteriolar resistance found in many cases of mitral stenosis. Parker and Weiss (1936), Larrabee et al. (1949), Henry (1952), and Harrison (1953) have demonstrated occlusive changes in the small arteries. The observations of Hickam and Cargill (1948), Bayliss et al. (1950a), and Holling (1952) that a rise in pulmonary artery pressure without a rise in cardiac output can occur in severe mitral stenosis on exercise, suggests a functional vasoconstriction, and this view has received support from Dexter et al. (1950) and Gorlin et al. (1951). Moreover, the narrowing of the small pulmonary arteries in patients with mitral stenosis and pulmonary hypertension which has been demonstrated by angiocardiography in life (Goodwin et al., 1952; Actis-Dato et al., 1952; Davies et al., 1953) has often been absent in post-mortem injection studies of lungs from such patients (Steiner and Goodwin, 1954). In addition, the frequent fall in arteriolar resistance following successful valvotomy, argues a reversible process (Werkö et al., 1953; Baker et al., 1952). The cause of the arteriolar constriction is not known, but it has been regarded teleologically as a protective phenomenon, shielding the pulmonary capillaries from the right ventricle (Lewis et al., 1952; Wood, 1952). Taquini et al. (1953) have suggested that since the increased arteriolar resistance imposes a severe load on the right ventricle, such patients follow a rapidly downhill course (" mitral stenosis with cor pulmonale"). Araujo and Lukas (1952) found that increased arteriolar resistance on exercise did not prevent large increases in pulmonary venous pressure in patients with mitral stenosis, and rejected the concept of a compensatory increase in pulmonary arteriolar resistance, believing this to be due primarily to anatomical narrowing of the arterioles.

\section{Hexamethonium Bromide and the Pulmonary Circulation}

The effect of hexamethonium bromide on the pulmonary circulation was investigated during cardiac catheterization in 12 patients with mitral valve disease and varying degrees of pulmonary hypertension. Gilmore et al. (1952) showed that, in patients with systemic hypertension, hexamethonium prevented the normal pulmonary vasoconstriction which occurs on assuming the upright position, and it was hoped that similar studies would shed further light on the autonomic control of the pulmonary vasculature in mitral stenosis, and might be of therapeutic significance in patients who were unsuitable for valvotomy. All the patients were investigated by cardiac catheterization to complete assessment of suitability for operation. Nine patients had mitral stenosis, three had predominant mitral incompetence, and two had additional significant aortic valve disease. Pulmonary hypertension of varying severity was present in all save four patients.

Methods. Cardiac catheterization was performed in the semi-recumbent position after preliminary sedation. Arterial oxygen saturation was measured either by oximetry, or by analysis of a specimen obtained by arterial puncture. The oxygen consumption was measured by Douglas bag and Haldane gas analysis, and blood samples were analysed in the Haldane blood gas apparatus (Bayliss et al., 1950b). The pulmonary arterial pressure was measured by strain gauge manometer in the resting state and recumbent 
position; the initial readings before hexamethonium were those recorded approximately 5 minutes after the catheter had been introduced into the pulmonary artery, and when the patient had settled down. The
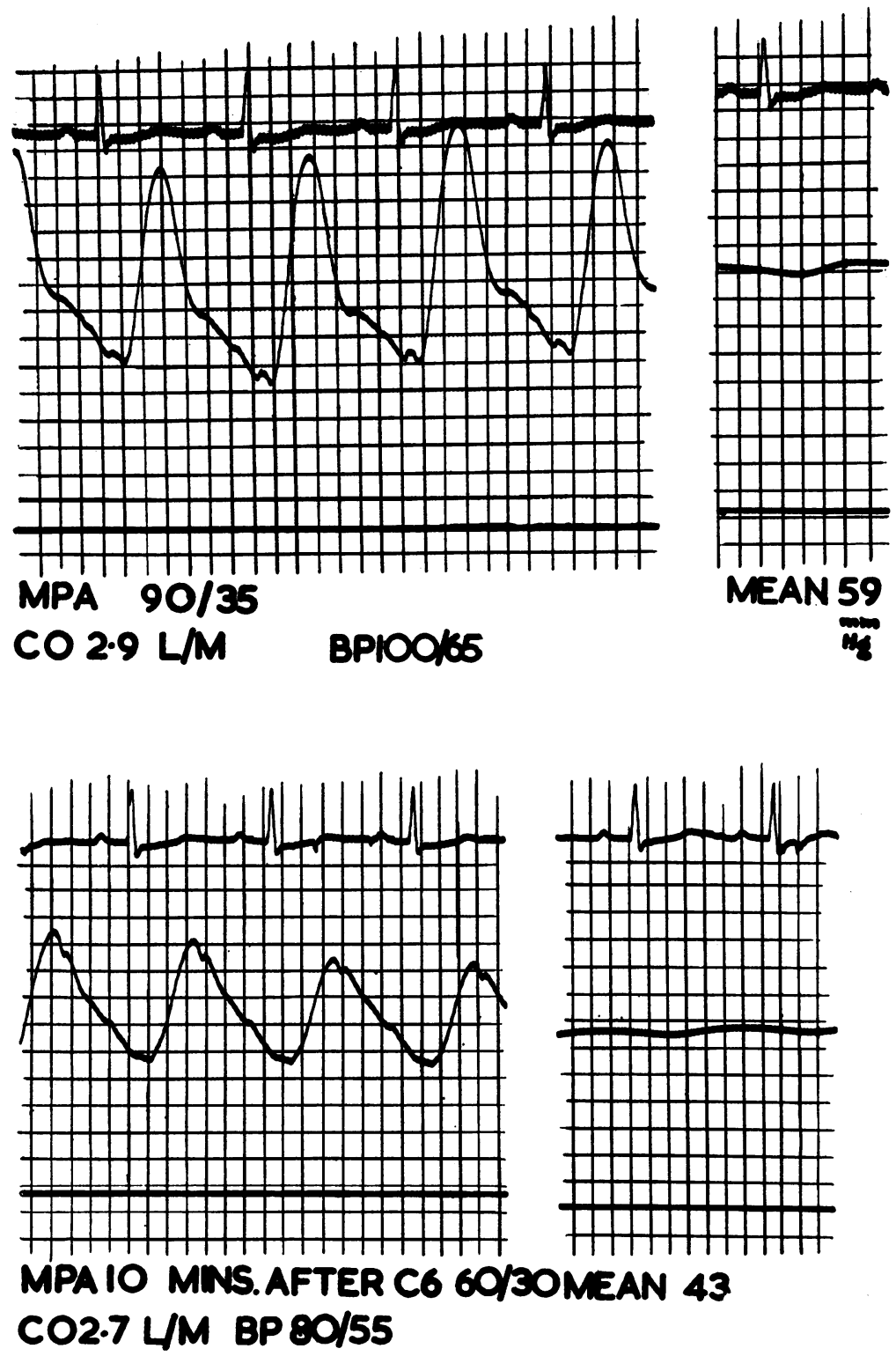

Fig. 1.-Case 2. Pulmonary arterial pressure, cardiac output, and systemic blood pressure before and after hexamethonium.

cardiac output was measured by the Fick principle, and the systemic blood pressure by strain gauge manometer connected to an indwelling arterial needle, or by sphygmomanometry.

In order to avoid the possibility of a fall in pulmonary arterial pressure being secondary to a profound fall in systemic blood pressure, the dose of hexamethonium bromide (usually $15-20 \mathrm{mg}$.) was determined by previous tests in each patient. The amount which produced a fall in the systolic arterial blood pressure of $10-20 \mathrm{~mm} . \mathrm{Hg}$ in the recumbent position was given. The pulmonary arterial pressure and systemic 
blood pressure were recorded at intervals after the injection of hexamethonium down the catheter, and the cardiac output measured after 15 minutes.

Results. In Cases 1-4, with severe pulmonary hypertension and systolic pulmonary arterial pressures between 55 and $90 \mathrm{~mm}$. $\mathrm{Hg}$, the administration of hexamethonium was followed by a marked fall in systolic pulmonary arterial pressure amounting to $30-40$ per cent of the resting figure, and this fall was maximal

\section{Effect of Hexamethonium on pulmonary circulation in mitral stenosis.}

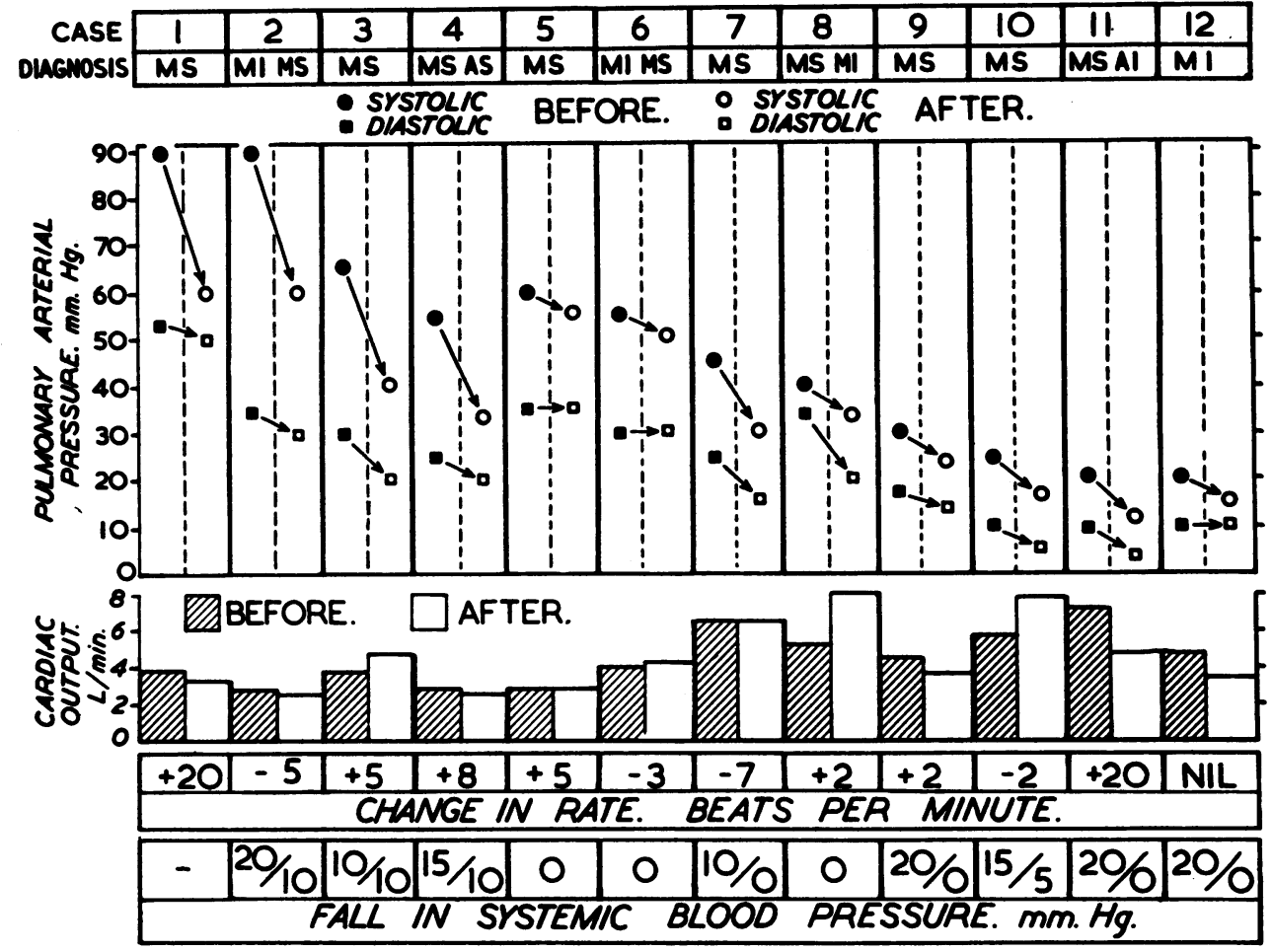

Fig. 2.-Effect of hexamethonium on the pulmonary arterial pressure, cardiac output, heart rate, and systemic blood pressure in 12 cases of mitral valve disease.

from 10 to 15 minutes after the injection. There was a much smaller fall in diastolic pulmonary arterial pressure. The systemic blood pressure fell much less than did the systolic pulmonary pressure. The cardiac output at this time showed no significant change in three patients, and a slight rise in the fourth. A slight increase in heart rate occurred in three patients, and a decrease in one.

In Cases 5, 6, and 8 no fall in systemic blood pressure occurred; sufficient hexamethonium was probably not given, which would account for the negligible fall in systolic pulmonary pressure in patients 5 and 6 , who had a high initial systolic pulmonary arterial pressure.

The remaining patients, who had slight or moderate pulmonary hypertension, or normal pressures, showed a small fall in pulmonary arterial pressure. This was within the variation normally encountered during the control period. These patients also showed considerable variations in cardiac output, consisting of an increase in Case 10, a small fall in Cases 9 and 12, and a greater fall in Case 11. They had clinically less severe mitral stenosis than Cases 1-8, and changes in output could have resulted from emotional or other factors. In two patients the pulmonary capillary pressure (Hellems et al., 1949) was measured before and after hexamethonium, a fall occurring in both patients. 
The fall in pulmonary arterial pressure without a fall in cardiac output in Cases 1, 2, 3, 4, and 7, indicates a reduction in total pulmonary vascular resistance. However, no such trend occurred in the patients without pulmonary hypertension (Cases 9-12) since the fall in pulmonary arterial pressure after hexamethonium was slight, and the cardiac output was variable. No definite deductions could be drawn from patients 5,6 , and 8 , since it is probable that insufficient hexamethonium was given.

\section{Discussion}

The fall in total pulmonary vascular resistance in patients with severe and moderately severe pulmonary hypertension cannot be fully explained on the data available. A shift of blood from the lungs to the peripheral vascular bed might be implicated in the fall in pulmonary resistance, but the fall in pulmonary arterial pressure was much greater than that in the systemic arterial pressure.

Pulmonary arteriolar dilatation seems the most likely explanation for the fall in total pulmonary resistance. The fact that the fall in pulmonary arterial pressure affected mainly the systolic component is not inconsistent with this hypothesis, since Fowler et al. (1952) found that the pulmonary arteriolar resistance was related as much to the systolic pressure as to the mean and diastolic pressures. If arteriolar dilatation is produced by hexamethonium, then autonomic influences are important factors in the production of arteriolar vasoconstriction.

Similar conclusions were reached by Fowler et al. (1950) who noted a fall in pulmonary pressure in 4 of 6 patients with pulmonary hypertension due to causes other than mitral stenosis, after tetra-ethyl ammonium chloride. Wilson and Keeley (1953) studied the effect of hexamethonium on the pulmonary arterial pressure in seven patients with pulmonary hypertension, two of whom had mitral stenosis. A fall in pulmonary arterial pressure occurred in both the latter patients, but was associated with a profound fall in systolic arterial pressure, a much larger dose of hexamethonium having been used.

\section{PULMONARY HYPERTENSION}

Hexamethonium has now been administered by us to a number of patients with mitral stenosis, and in none of these have we noted any untoward effects, such as dyspnœa, or pulmonary œdema. This indicates that reduction in pulmonary arterial pressure in severe pulmonary hypertension can be without harmful influence. We have also given hexamethonium to two patients with pulmonary œdema due to mitral stenosis. In one case, in which no other treatment had been given, there was dramatic relief of dyspnca and disappearance of pulmonary râles. In the other patient hexamethonium was given after the usual therapy had failed to produce significant improvement, and was followed by resolution of the œdema. Studies are continuing on the effect of hexamethonium on pulmonary odema in mitral stenosis.

We have been impressed by the greater severity of the symptoms and poorer prognosis in patients with mitral stenosis who have severe pulmonary hypertension than in those with slight or moderately raised pulmonary arterial pressure. It seemed to us that the former patients, like those mentioned by Taquini et al. (1953), pursued a rapidly downhill course, and that severe pulmonary hypertension is a factor in worsening prognosis. It is, of course, true that patients who have high pulmonary capillary pressures but a low arteriolar resistance may have attacks of severe pulmonary œdema (Baker et al. 1952), but it has been our impression that such attacks are more common in patients with severe pulmonary hypertension.

We have therefore examined the relationship between attacks of paroxysmal dyspnœa, and paroxysmal orthopnca on the one hand, and severe pulmonary hypertension on the other, in 103 patients with mitral valve disease. The pulmonary arterial pressure at rest had been measured in 51 of these, 22 of whom gave a history of attacks of spontaneous dyspnœa or orthopnœa, while 29 had no such history (Fig. 3). Taking an arbitrary level of $60 \mathrm{~mm}$. Hg for the systolic pulmonary arterial pressure (which may be assumed to indicate arteriolar constriction), $13(59 \%)$ in the first group had pulmonary arterial pressures above this figure. By contrast, only $7(24 \%)$ in the second group had a systolic pulmonary arterial pressure of $60 \mathrm{~mm}$. $\mathrm{Hg}$ or above. There is a significant 
correlation between systolic pressures greater than $60 \mathrm{~mm}$. $\mathrm{Hg}$ and paroxysmal dyspncea or orthopnca on the one hand, and between pressures of less than $60 \mathrm{~mm}$. $\mathrm{Hg}$ and lack of these symptoms, on the other $\left(x^{2}=6 \cdot 4\right)$. The pulmonary arterial pressure was assessed radiologically by examination of changes in the pulmonary arteries in the same 51 patients and in an additional

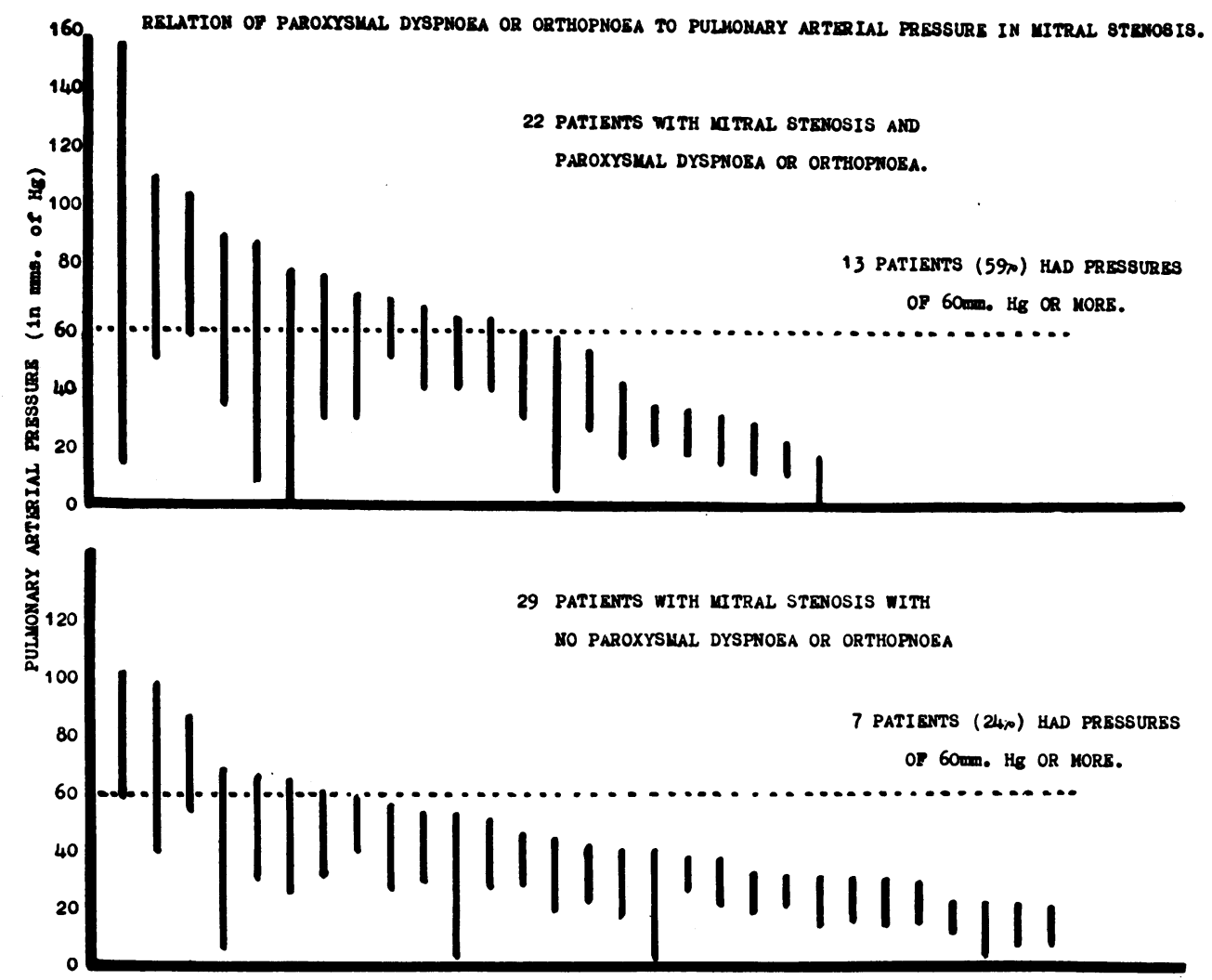

FIG. 3.-Relationship between history of paroxysmal dyspnœa or orthopnœa and pulmonary arterial pressure in 51 patients with mitral valve disease.

52 patients in whom the pulmonary arterial pressure was not measured by cardiac catheterization. Fig. 4 shows that of 43 patients with paroxysmal dyspnœa or orthopnœa, 53 per cent had changes in the lungs indicative of a systolic pulmonary arterial pressure of $60 \mathrm{~mm}$. $\mathrm{Hg}$ or more (Grade II), while 35 per cent had less severe changes (Grade I) indicating a pressure of less than $60 \mathrm{~mm} . \mathrm{Hg}$, and only 12 per cent had no changes (indicating a normal pulmonary arterial pressure). Of 60 patients with no paroxysmal dyspnœa, only 25 per cent had high pressure changes in the lungs, 43 per cent had moderate changes, and 32 per cent had no radiological pulmonary arterial abnormalities, indicating a normal pulmonary arterial pressure. There is a significant correlation between paroxysmal dyspnœa or orthopnœa and severe pulmonary hypertension (Grade II) on the one hand, and between absence of these symptoms and minimal or moderate hypertension (Grade 0 or 1$)$, on the other $\left(x^{2}=8 \cdot 7\right)$. Predominant mitral incompetence occurred with equal frequency in patients with and without paroxysmal dyspnœa.

These results tend to confirm our clinical impression that severe pulmonary hypertension is associated with attacks of dyspnœa, and suggests that the increased arteriolar resistance may not be "protective" in nature. The absence of any untoward symptoms or dyspnœa after hexa- 
methonium, which has been shown to lower the vascular resistance in severe pulmonary hypertension, further suggests that the concept of protective arteriolar constriction would bear re-examination. However, until the exact mode of action of hexamethonium upon the pulmonary circulation is known, this matter cannot be settled conclusively. We believe, however, that severe pulmonary hypertension is a serious complication of mitral stenosis, indicating a poor prognosis, and is associated with steady deterioration in the condition of the patient. Mitral valvotomy benefits many of these patients, who may show a fall in pulmonary arteriolar resistance as a result (Werkö et al., 1953; Baker et al., 1952). Hexamethonium might be of value in the treatment of patients with severe pulmonary hypertension who are unsuitable for valvotomy because of predominant mitral incompetence or for other reasons, or in the treatment of attacks of paroxysmal dyspnœa due to mitral stenosis.

60 PATIENTS.

NO PAROXYSMAL DYSPNOEA

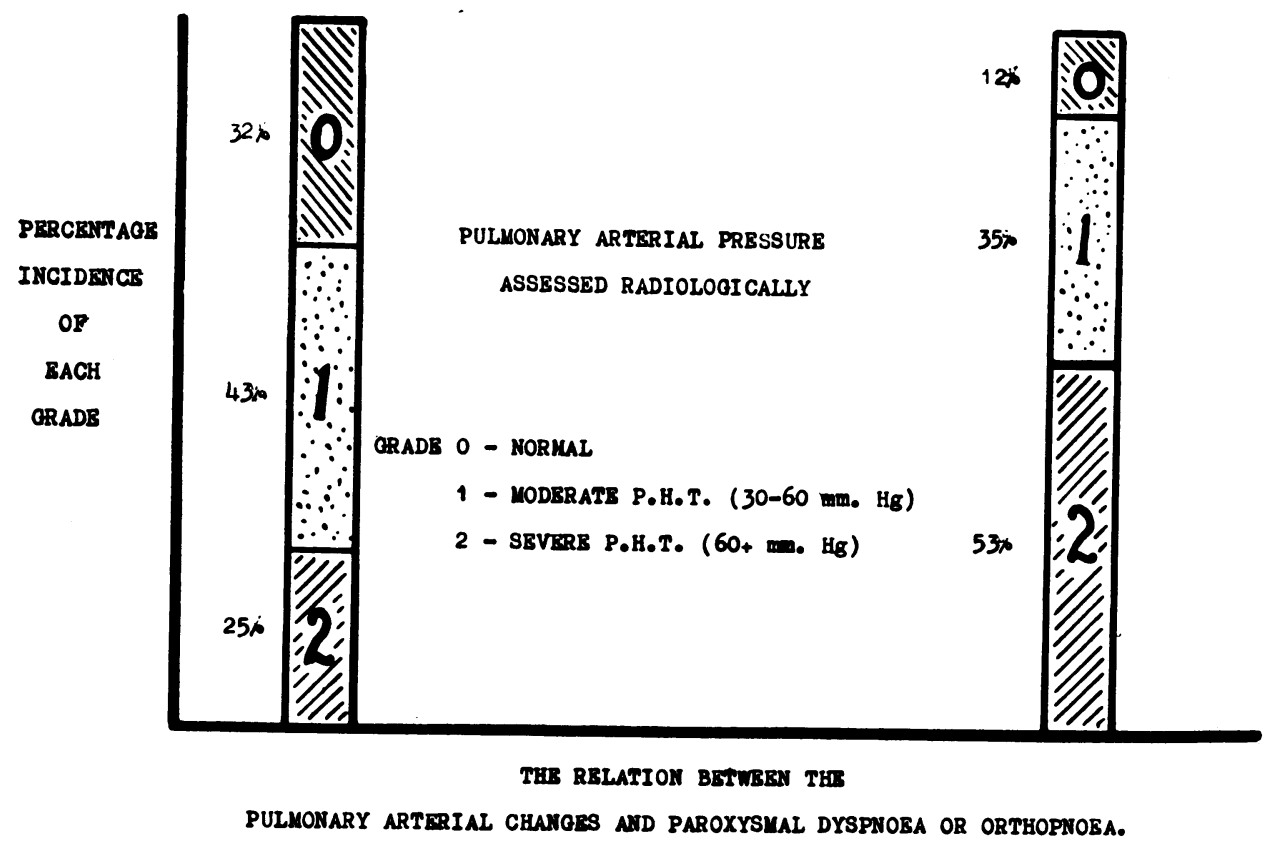

43 PATIBNTS.

WITH PAROXYSMAL DYSPNOEA OR ORTHOPNOEA

FIG. 4.-Relationship between radiological evidence of pulmonary hypertension and a history of symptoms
of paroxysmal orthopnœa or dyspnœa in 103 patients with mitral valve disease.

\section{SUMMARY}

Hexamethonium bromide, administered during cardiac catheterization, was found to produce a sharp fall in pulmonary arterial pressure without a fall in cardiac output in patients with severe pulmonary hypertension due to mitral stenosis. This reduction in total pulmonary vascular resistance is considered to be due probably, though not certainly, to arteriolar dilatation. If this is so, then these results provide further evidence of a reversible narrowing of the pulmonary arterioles, which must be mediated, at least in part, through the autonomic nervous system. The implications of these findings are discussed, with particular reference to the association between paroxysmal dyspnœa and pulmonary hypertension in mitral stenosis. Analysis of 103 cases of mitral stenosis indicated that attacks of paroxysmal dyspnœa or orthopnœa were more frequent in patients with active pulmonary hypertension than in those without. It is suggested that 
pulmonary arteriolar constriction may not always be protective in nature, that active pulmonary hypertension represents a severe complication of mitral stenosis, and that hexamethonium might prove useful in the treatment of attacks of paroxysmal dyspnœa, or of pulmonary hypertension in patients who are unsuitable for valvotomy.

We wish to express our appreciation to Dr. Richard Turner, whose example prompted this work, and to Professor McMichael for much helpful criticism and advice. We would also like to thank Mrs. Angela Birbeck and Mr. J. MacNaughton for valuable technical assistance. We are indebted to Mr. Graham for the figures.

\section{REFERENCES}

Actis-Dato, A., Angelino, P. A., and Zambelli, E. (1952). Minerva Medica, 43, 695.

Araujo, J., and Lukas, D. S. (1952). J. clin. Invest., 31, 1082.

Baker, C., Brock, R. C., Campbell, M., and Wood, P. (1952). Brit. med. J., 1, 1043.

Bayliss, R. I. S., Etheridge, M. J., and Hyman, A. L. (1950a). Lancet, 2, 889.

$\frac{1}{-}, \frac{1}{,}$, Hyman, A. L., Kelly, H. G., McMichael, J., and Reid, E. A. S. (1950b). Brit. Heart J., $12,317$.

Davies, L. G., Goodwin, J. F., Steiner, R. E., and Van Leuven, B. D. (1953). Brit. Heart J., 15, 393.

Dexter, L., Dow, J. W., Haynes, F. W., Whittenberger, J. L., Ferris, B. G., Goodale, W. T., and Hellems, H. K. (1950). J. clin. Invest., 29, 602.

Fowler, N. O., Westcott, R. N., Hauenstein, V. D., Scott, R. C., and McGuire, J. (1950). J. clin. Invest., $29,1387$.

, and Scott, R. C. (1952). J. clin. Invest., 31, 72.

Gilmore, H. R., Kopelman, H., McMichael, J., and Milne, I. G. (1952). Lancet, $2,898$.

Goodwin, J. F., Steiner, R. E., and Lowe, K. G. (1952). J. Fac. Radiol., 4, 21.

Gorlin, R., Haynes, F. W., Goodale, W. T., Sawyer, C. G., Dow, J. W., and Dexter, L. (1951). Amer. Heart J., $41,30$.

Harrison, C. V. (1953). Personal communication.

Hellems, H. K., Haynes, F. W., and Dexter, L. (1949). J. appl. Physiol., 2, 24.

Henry, E. W. (1952). Brit. Heart J., 14, 406.

Hickam, J. B., and Cargill, W. H. (1948). J. clin. Invest., 27, 10.

Holling, H. E. (1952). Brit. med. Bull., 8, 358.

Larrabee, W. F., Parker, R. L., and Edwards, J. E. (1949). Proc. Mayo Clin., 24, 316.

Lewis, B. M., Gorlin, R., Houssay, H. E. J., Haynes, F. W., and Dexter, L. (1952). Amer. Heart J., 43, 2.

McGregor, M., Bothwell, T. H., Zion, M. M., and Bradlow, B. A. (1953). Amer. Heart J., 46, 187.

Parker, F., and Weiss, S. (1936). Amer. J. Path., 12, 573.

Steiner, R. E., and Goodwin, J. F. (1954). J. Fac. Radiol., 5, 167.

Taquini, A. C., Donaldson, R. J., Ballina, E. S., D'Aiutolo, R. E. H., and Lozada, B. B. (1953). Amer. Heart J., 45, 691 .

Werkö, L., Biörck, G., Crafoord, C., Wulff, H., Krook, H., and Eliasch, H. (1953). Amer. Heart J., $45,477$.

Wilson, V. H., and Keeley, K. J. (1953). S. Afr. J. med. Sci., 18, 125. 